\title{
Curing Color Blindness-Mice and Nonhuman Primates
}

\author{
Maureen Neitz and Jay Neitz \\ Department of Ophthalmology, University of Washington, Seattle, Washington 98109 \\ Correspondence: mneitz@uw.edu
}

It has been possible to use viral-mediated gene therapy to transform dichromatic (red-green color-blind) primates to trichromatic. Even though the third cone type was added after the end of developmental critical periods, treated animals acquired red-green color vision. What happened in the treated animals may represent a recapitulation of the evolution of trichromacy, which seems to have evolved with the acquisition of a third cone type without the need for subsequent modification to the circuitry. Some transgenic mice in which a third cone type was added also acquired trichromacy. However, compared with treated primates, red-green color vision in mice is poor, indicating large differences between mice and monkeys in their ability to take advantage of the new input. These results have implications for understanding the limits and opportunities for using gene therapy to treat vision disorders caused by defects in cone function.

$V^{i}$ sual experience-dependent neural plasticity is a recognized property of the developing cortex, but what purpose is served by the ability of sensory processes to remodel their function in response to changes in experience (Hubel 1988)? An engaging hypothesis is that plasticity relieves the necessity to hard-wire all connections during development according to genetic instructions. In the adult cortex, this could allow adaptive adjustments depending on the environment and could provide a mechanism for recovering from damage (Albright et al. 2000). Classic visual deprivation experiments led to the expectation that neural connections established during development would not appropriately process an input that was not present from birth, and therefore, that treatment of con- genital vision disorders would be ineffective unless administered to the very young. However, in recent experiments using adult red-green colordeficient primates, addition of a third opsin was sufficient to produce trichromatic color vision behavior (Mancuso et al. 2009), demonstrating that trichromacy does not require an early developmental process and that there are exceptions to the idea that neural inputs to the visual system cannot be appropriately processed unless they are established before a critical period in development. For example, in a recent study of surgical outcome for removal in congenital cataracts in pediatric patients, poor outcomes were associated with surgical intervention after compared with before one year of age (Khanna et al. 2013). The successes so far provide reason

Editors: Eric A. Pierce, Richard H. Masland, and Joan W. Miller

Additional Perspectives on Retinal Disorders: Genetic Approaches to Diagnosis and Treatment available at

www.perspectivesinmedicine.org

Copyright (C) 2014 Cold Spring Harbor Laboratory Press; all rights reserved; doi: 10.1101/cshperspect.a017418

Cite this article as Cold Spring Harb Perspect Med 2014;4:a017418 
for optimism that gene therapy can be developed as a viable treatment strategy for adult patients with disorders affecting cone photoreceptor function, and they open the way for new research to explore the possibilities and limits for gaining function by adding new inputs in adults. A better understanding of the ways in which the adult nervous system changes and does not change will be key for future development of therapies to restore visual function.

\section{CURING COLOR BLINDNESS IN NONHUMAN PRIMATES}

Experiments using gene therapy in an attempt to cure congenital red-green color blindness in nonhuman primates were performed on adult squirrel monkeys (Saimiri sciureus). In this species, as in many other New World primates, there is a single opsin gene on the $\mathrm{X}$ chromosome, but there is allelic diversity at the locus (Jacobs 1984; Mollon et al. 1984; Jacobs and Neitz 1985; Soares et al. 2010; Bunce et al. 2011). One allele encodes the equivalent to a human long-wavelength (L) opsin; another encodes the equivalent to a human middle-wavelength (M) opsin; and at least one allele encodes an opsin that gives rise to a photopigment that is spectrally intermediate between human $\mathrm{L}$ and $\mathrm{M}$ photopigments (Neitz et al. 1991; Jacobs et al. 1993). Because all male squirrel monkeys have only one $\mathrm{X}$ chromosome, they are dichromatic, with one cone photopigment encoded by the X chromosome plus a short wavelength (S)-sensitive cone photopigment encoded by an autosome. Females who are homozygous for the cone opsin allele encoded by the X chromosome are also dichromatic; however, females who are heterozygous have trichromatic color vision (Jacobs and Neitz 1987). The process of $X$ inactivation segregates the expression of the two opsin alleles into separate populations of cone photoreceptors, giving rise to a mosaic containing $\mathrm{L}, \mathrm{M}$, and $\mathrm{S}$ cones.

\section{Gene Therapy with L Opsin in Dichromatic Squirrel Monkeys}

The gene therapy trials targeted adult squirrel monkeys that were missing the gene encoding $\mathrm{L}$ opsin. Adeno-associated virus serotype $2 / 5$ (rAAV2/5) containing a recombinant human L-opsin (RHLOPS) gene under the control of the recombinant human $\mathrm{L} / \mathrm{M}$-opsin enhancer and promoter pR2.1 (Wang et al. 1992) was delivered to the photoreceptor layer by subretinal injection (Mancuso et al. 2009). Transcriptional regulatory elements contained in pR2.1 direct gene expression in $\mathrm{M}$ cones, but not $\mathrm{S}$ cones, rods, or any other retinal cell type (Li et al. 2007). These control elements include the locus control region, which is an enhancer that is required for transcription of the opsin genes on the $\mathrm{X}$ chromosome (Nathans et al. 1989; Wang et al. 1992; Wang et al. 1999), and the proximal promoter for the L-opsin gene. To provide the receptor basis for trichromacy, animals received three $100-\mu \mathrm{L}$ injections in each eye. This transduced roughly one-third of the $\mathrm{M}$ cones such that they coexpressed the transgenic L opsin along with the endogenous $M$ opsin, whereas the untransduced $M$ cones expressed only the endogenous $M$ opsin. The transduced- and wild-type cones were randomly intermixed in a relatively smooth mosaic. Before treatment, monkeys were trained to perform a computer-based color vision test, the Cambridge Colour Test (Reffin et al. 1991; Regan et al. 1994), which had been modified for use with animals (Fig. 2) (Mancuso et al. 2006). All dichromats, including humans and monkeys who are missing either the L- or the $\mathrm{M}$ photopigment, fail to distinguish from gray any colors near the "spectral neutral point" located in the blue-green region of color space. They also fail to distinguish complementary colors near the "extra-spectral neutral point" in the red-violet region (Jacobs 1984). Trichromats experience six basic color percepts that exist as opponent pairs: blue and yellow, red, and green, and black and white. In contrast, dichromats experience only four basic color percepts, nominally blue and yellow, and black and white, but they do not experience the normal sensations of red or green (Schmidt et al. 2014). For all dichromats there are two colors that are indistinguishable from gray, one of which appears greenish and the other reddish to normal trichromats. 
Before treatment, two dichromatic monkeys completed three complete color vision tests (Mancuso et al. 2009). Each test examined the animal's ability to discriminate 16 different hues from gray. For each hue, thresholds were determined for how much color had to be added to a gray stimulus for it to be distinguishable from a gray background. Because 4-6 mo were required to test all 16 hues, baseline results represented testing conducted for $>1 \mathrm{yr}$. As predicted, before treatment, the monkeys had low thresholds for colors that represent blues and yellows to their dichromatic eyes. They always failed to discriminate specific blue-green and red-violet hues from gray, as is characteristic of animals and humans with only $S$ and $M$ cones (protanopes). Their pretreatment thresholds, extrapolated from psychometric functions, were orders of magnitude higher for colors that activate the normal red-green system and fall along a "protan line" in color space than for colors that maximally activate the blue-yellow color opponent system and that fall along a "tritan line" (a color confusion line for people with defects in S cones). Results were highly repeatable, with no improvement between the first and third tests, demonstrating that the animals do not spontaneously improve in the absence of treatment.

Coexpressing the L-opsin transgene within a subset of endogenous $M$ cones shifted their spectral sensitivity, allowing the transduced $\mathrm{M}$ cones to respond to long-wavelength light (Mancuso et al. 2009). This produced two distinct cone types absorbing in the middle-tolong wavelengths: " $\mathrm{M}+\mathrm{L}$ " and $\mathrm{M}$. Thus, together with $\mathrm{S}$ cones, the treated animals had three cone types, as required for trichromacy. The spectral sensitivity shift was readily detected using a custom-built, wide-field, color multifocal electroretinogram (mf-ERG) system (Kuchenbecker et al. 2008). In experiments performed on separate animals that were not involved in behavioral testing, the color mf-ERG was validated by treating an animal with a mixture of two viral vectors that were identical except that one carried the human L-opsin gene whereas the other carried the gene for humanized green fluorescent protein (GFP). Faint GFP fluores- cence was first detected at 9 wk postinjection, and it continued to increase in area and intensity for $>24$ wk (Mancuso et al. 2009). Although faint signs of GFP were first detectable at $9 \mathrm{wk}$, L-opsin levels sufficient to produce suprathreshold mf-ERG signals were still not present at 16 wk postinjection. After GFP fluorescence became robust, the $\mathrm{mf}-\mathrm{ERG}$ response to red light, which indicates responses from the introduced L opsin, showed highly increased response amplitudes in the area of treated retina. The two dichromatic monkeys who participated in behavioral tests of color vision were treated only with the virus carrying the L opsin gene. The treatment goal of producing a large homogeneous region was accomplished by placing injections at three well-spaced locations with centers corresponding to $\sim 10^{\circ}$ eccentricity from the fovea. This produced an mf-ERG response to red light that covered an area of central retina of roughly $100^{\circ}$ in diameter. The wide-field color mf-ERG results showed that gene therapy changed the spectral sensitivity of a subset of the cones.

A priori, there were two possibilities for how a change in spectral sensitivity might change color vision behavior. First, animals may have had an increase in sensitivity to long-wavelength light, but if the neural circuitry for extracting color information from the nascent " $\mathrm{M}+\mathrm{L}$ cone" submosaic was absent, they would remain dichromatic - the hallmark of which is having two hues that are indistinguishable from gray (i.e., the spectral neutral point, and extraspectral neutral point). The spectral neutral point for individuals that have only $\mathrm{S}$ and $\mathrm{M}$ cones, as the monkeys had before therapy, occurs near the dominant wavelength of $495 \mathrm{~nm}$. At the limit, an increase in spectral sensitivity would shift the monkeys' neutral point toward that of individuals with only $\mathrm{S}$ and $\mathrm{L}$ cones, near the dominant wavelength of $505 \mathrm{~nm}$. Thus, there would be a shift in blue-yellow color vision caused by the increased sensitivity to red light produced by the added human L cone photopigment; however, the animal could still have dichromacy.

The second, more engaging possibility is that treatment would be sufficient to expand 
sensory capacity in monkeys, providing them with trichromatic vision. The change in spectral sensitivity measured with the wide-field color mf-ERG is necessary but not sufficient to produce a new capacity for color vision. To give another example, individuals with $\mathrm{L}$ cones but no $\mathrm{M}$ cones (termed deuteranopes) have a relatively enhanced sensitivity to red light, but they are still as dichromatic as individuals with $\mathrm{M}$ cones but no $\mathrm{L}$ cones (protanopes) in that they are unable to distinguish particular colors (i.e., their spectral and extraspectral neutral points) from gray. In addition to neural pathways carrying blue-yellow color information about the relative spectral distribution of short versus long wavelength light, dichromats have visual channels carrying achromatic information about the relative "brightness" or luminance of objects compared with their surroundings. To determine if the animals had acquired a third neural channel carrying red-green information, it was necessary to prove that the changes in the animals' behavior were not just manifestations of changes in the achromatic and blue-yellow systems induced by the change in spectral sensitivity following addition of the L pigment. In the Cambridge Colour Test (Fig. 1) used to measure color discrimination in the monkeys, both the stimulus and the background are made up of dots that incorporate random luminance variation, which makes brightness a nonrelevant cue for detection. Luminance adjustments were made in the stimulus to ensure that brightness could not be a cue for detection, and under all conditions the treated monkeys made discriminations that were impossible for untreated animals. To confirm that the behavioral change observed in animals expressing the transgenic $\mathrm{L}$ pigment was not purely a shift in spectral sensitivity, monkeys were also tested using the dominant wavelengths that could represent all possible dichromacies based on $\mathrm{S}$ versus $(\mathrm{L}+\mathrm{M})$ pigments in which $\mathrm{L}$ and $\mathrm{M}$ might exist in different proportions. Together, these dominant wavelengths span the possible confusion points for deuteranopes and protanopes and for any

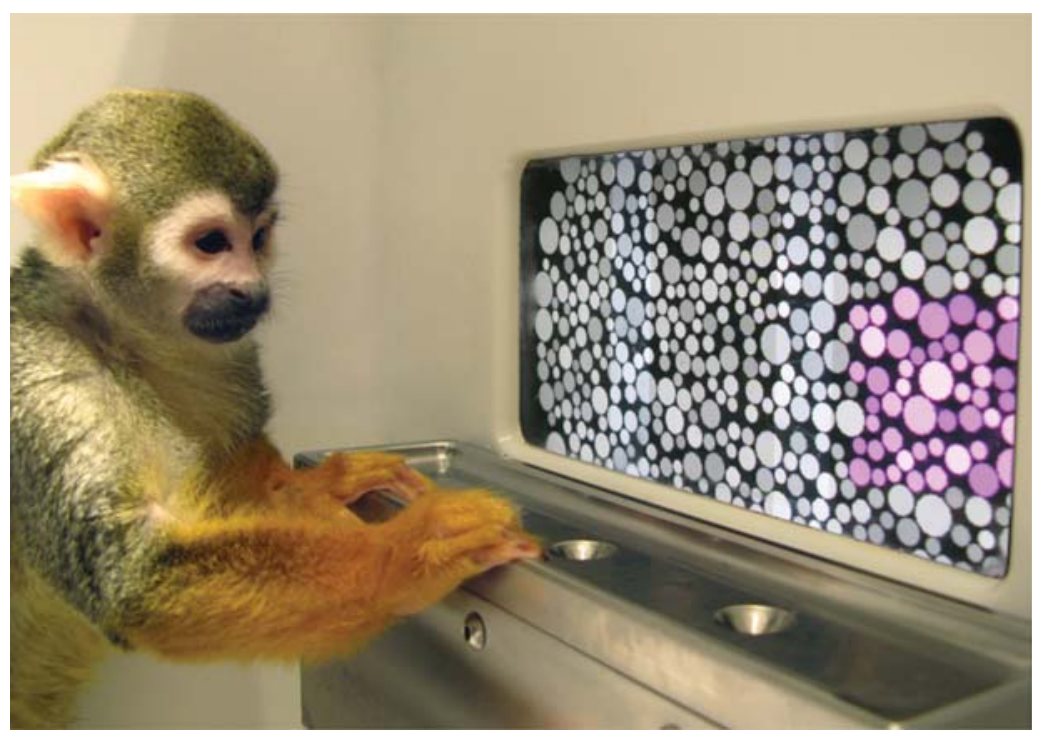

Figure 1. Color vision assayed using the Cambridge Colour Test. In this test, adapted for use with animals, the animal's task is to locate the blob of color against a background of gray dots using the touch-sensitive screen. Over trials, the positive stimulus randomly appears in one of three positions. The amount of color in the positive stimulus is reduced over trials to determine the amount needed to produce a threshold. Both stimulus and background dots vary in intensity making it impossible for the animal to locate the "blob" based on brightness cues. The animal has to use color vision to detect differences in the spectral distribution of light in the stimulus compared with the background. 
intermediate dichromatic forms that could arise from expressing combinations of $\mathrm{L}$ pigments or combinations of $\mathrm{M}$ pigments (Neitz and Neitz 2011). The measured thresholds for the treated monkeys were low for all the dominant wavelengths tested, demonstrating that the monkeys lacked a spectral neutral point and had acquired a neural channel carrying red-green color vision, and as such were truly trichromatic. The treated animals discriminated colors in the red range from those in the green range and distinguished both from gray; they also discriminated between other color combinations that dichromats find impossible to tell apart. The finding that the treated monkeys were able to discriminate blue-green when it was tested against a red-violet background instead of the gray background indicated that the monkeys' newly acquired "green" and "red" percepts were distinct from one another.

\section{A Possible Evolutionary Mechanism for a Shift from Dichromacy to Trichromacy}

Classic experiments in which visual deprivation of one eye during development caused permanent vision loss led to the idea that visual inputs must be present during development for the formation of circuits to process the visual information (Hubel and Wiesel 1970). From the clear change in behavior associated with treatment, compared both between and within subjects (Mancuso et al. 2009), we conclude that the adult monkeys gained new color vision capacities because of gene therapy. These startling empirical results provide insight into the evolutionary changes in the visual system that are required for adding a new dimension of color vision. Previously, it seemed possible that a transformation from dichromacy to trichromacy would require evolutionary and developmental changes, for instance, the development of new neural circuitry in later structures along the pathway to vision-in addition to acquiring a third cone type. However, results from squirrel monkeys show that a transformation from dichromatic to trichromatic color vision behavior can occur with the addition of a third cone type after the visual system has developed.
The acquisition of new color vision was also shown in genetically engineered mice (Jacobs et al. 2007); however, the point has been made that such plasticity need not indicate that any rewiring of the neural circuitry has occurred (Makous 2007). Indeed, given that new color vision behavior in adult squirrel monkeys was observed just as levels of transgene expression became robust, we conclude that rewiring of the visual system was not associated with the change from dichromatic to trichromatic vision. We suggest that gene therapy with a new opsin recapitulates what occurred during evolution of trichromacy in primates. These experiments show that a new capacity for color vision, as defined by new discrimination abilities, can use preexisting neural circuitry. Moreover, results from squirrel monkeys suggest that full trichromatic color vision could have evolved solely by adding a gene for a third cone pigment, in the absence of any other genetic change in the visual system specific to red-green color vision. These experiments to cure color blindness are the first to use gene therapy in primates to treat a vision disorder in which all photoreceptors are intact and healthy, making it possible to assess the full potential of gene therapy to manipulate visual capacities.

\section{Neural Plasticity: Implications for Treatment of Retinal Disorders}

Treatment allowing monkeys to see new colors in adulthood provides a striking counter-example to what occurs under conditions of monocular deprivation. For instance, it is impossible to restore vision in an adult who has grown up with a unilateral congenital cataract (Birch and Stager 1996). Future technologies may allow opportunities for functions to be added or restored in the eye. Although some changes may produce irreversible outcomes analogous to monocular deprivation, others, like gene therapy for red-green color blindness, may provide new vision capabilities.

Even before the advent of gene therapy, the neural mechanisms underlying color vision were thought to represent an interesting model system for understanding neural plasticity. 
Color vision may be an example of experience guiding neural function in the visual system. For example, there is amazing variation in the ratio of $\mathrm{L}$ to $\mathrm{M}$ cones in the retina (Hagstrom et al. 1998; Roorda and Williams 1999; Carroll et al. 2000; Hofer et al. 2005), yet individuals with very different ratios are not correspondingly different in their color vision-they are all categorized as having normal trichromacy by standard color vision tests (Pokorny et al. 1991; Jordan and Mollon 1997; Miyahara et al. 1998; Brainard et al. 2000). This indicates that the red/green chromatic system is able to adjust to produce the same vision in individuals with large differences in their cone mosaics.

New World primates are an exact genetic model of inherited red-green color blindness in humans and provide an interesting insight into visual plasticity. Most mammals have two types of cone photoreceptors: $S$ and M/L. These two cone types are the basis for dichromatic color vision. In contrast, Old World primates are usually trichromatic, having the $\mathrm{S}$ cones and two spectrally distinct M/L cones. For example, humans have $\mathrm{M}$ and $\mathrm{L}$ cones separated in peak sensitivity by $20-30 \mathrm{~nm}$. Genetic evidence suggests that uniform trichromacy arose from allelic trichromacy via a gene translocation that placed $\mathrm{M}$ and $\mathrm{L}$ pigment genes in tandem on the X chromosome (Nathans et al. 1986a,b; Vollrath et al. 1988). Most New World primates, including squirrel monkeys, show allelic trichromacy (a single gene for cone opsin with multiple alleles forming spectrally distinct pigments), which appears to be an evolutionary intermediate between Old World primates and other mammals. The majority of all squirrel monkeys are dichromatic, but about $2 / 3$ (the heterozygous females) are trichromatic, and the visual system is plastic enough support both types of vision as normal variants.

\section{Possible Neural Networks Used by Newly Trichromatic Primates}

In the retina, there are spectrally opponent cells that are believed to serve color vision via two distinct, spectrally opponent pathways: redgreen and blue-yellow. Gene therapy for color blindness in adult primates provides insight into the role of early visual experience in the development of color vision circuitry. Because of the capricious nature of viral transduction, one virtue of gene therapy for color blindness is that it produces a random mosaic of cones that closely mimics that of naturally occurring trichromats. How, then, do treated animals extract a new dimension of color vision from their new cone complement?

The squirrel monkeys might form the circuitry underlying red-green color vision by adapting components that were not previously involved in color vision in dichromats. An alternative could be called the "blue-yellow" hypothesis, in which the addition of the third cone class split formerly $S$ versus $M$ receptive fields into two types with differing spectral sensitivities. Adapting a portion of one color system to provide a new visual dimension could obviate the need for neural rewiring as part of the process of adopting new color vision (Shapley 2009; Neitz and Neitz 2011).

\section{RECENT EVIDENCE POINTS TO A NEW HYPOTHESIS FOR THE BIOLOGICAL BASIS OF TRICHROMACY IN PRIMATES}

The textbook version of the standard model for the physiological basis for trichromatic color vision is that blue-yellow color vision is based on retinal small bistratified $\mathrm{S}-(\mathrm{L}+\mathrm{M})$ cells and red-green color vision is based on (L-M) and (M-L) midget ganglion cells (DeValois and DeValois 1993; Dacey 2000). If correct, then human perceptions should be predictable from the responses of those cells; however, there are conspicuous differences between human color vision and what is predicted from the responses of $\mathrm{S}-(\mathrm{L}+\mathrm{M})$ and $\mathrm{L}$ versus $\mathrm{M}$ cells (DeValois and DeValois 1993). The contradiction between human perception and $\mathrm{L}$ versus $\mathrm{M}$ midget ganglion cell responses arises because $\mathrm{S}$ cones have an input to perceptual redness and greenness but they do not have an input to the putative canonical (L-M) "red-ON" and (M-L) "green-ON" midget ganglion cells of the standard model (Drum 1989; DeValois and DeValois 1993; Dacey 2000). Excitatory S-cone input contributes 
to the perception of both blue and red and inhibitory S-cone input contributes to the perceptions of both yellow and green. DeValois and DeValois (1993) proposed the addition of a third stage of processing at a higher level of the visual pathway that "rotates" the color axes of the cells in the lateral geniculate nucleus to give rise to the red-green and yellow-blue axes of perceptual color space.

Several recent findings have led us to propose an alternative neurobiological explanation for color appearance and hue perception (Schmidt et al. 2014), and this alternative also provides a simple explanation for why gene therapy "cures" color blindness in adult squirrel monkeys. S-cone inputs to small bistratified cells are mediated by S-cone bipolar cells and these are specifically ON-type bipolar cells. Humans with mutations in the GRM6 gene encoding the metabotropic glutamate receptor (mGluR6) specific to ON bipolar cells have no means to transmit any $\mathrm{ON}$ responses to the inner retina, and thus lack S-cone input to the small bistratified ganglion cell, yet these individuals have normal color perception (Terasaki et al. 1999; Dryja et al. 2005; Neitz and Neitz 2011). This flatly contradicts the prediction of the standard model. These findings thus suggest that the small bistratified cell is not responsible for conscious color perception.

A possible alternative is as follows: There are two recent reports demonstrating that synaptic elements for GABAergic feed-forward signaling between HII horizontal cells and midget bipolar cells, which is enhanced in primates' $S$ cones, compared with mice or ground squirrels (Puller et al. 2014a,b). These findings suggest that the feed-forward mechanism may have evolved in primates for the purpose of color vision. The GABA-mediated feed-forward mechanism would specifically inject S-cone input into the midget bipolar cells of adjacent $\mathrm{L} / \mathrm{M}$ cones. To explain hue appearance, S-cone signals have to be combined with $\mathrm{M}$ versus $\mathrm{L}$ opponent signals in two different ways to produce red-green and blue-yellow axes that match human perceptions, but only a small subset of midget ganglion cells need to carry S-cone signals to account for hue perception. Recordings from large samples of cells in the lateral geniculate nucleus (Tailby et al. 2008) have identified a group of cells that have input from $M$ cones with the same sign as $\mathrm{S}$ cones, for instance, they are $(S+M)-L$ cells that we propose are the retinal locus responsible for blue perception (Schmidt et al. 2014). Moreover, one population of cells in the lateral geniculate nucleus had $\mathrm{L}-(\mathrm{S}+\mathrm{M})$ inputs as required for the yellow side of blue-yellow hue opponency and as predicted by the hypothesis that S-OFF signals may be injected directly into midget bipolar cells by the proposed GABA feed-forward mechanism. Because the only cells in the retina known to carry opponent signals from $\mathrm{M}$ versus $\mathrm{L}$ cones are midget ganglion cells, these results could reflect the existence of a small subclass of midget ganglion cells that are the substrate for hue perception. Thus, we argue that there are two populations of midget ganglion cells, one of which makes up the majority, which are the standard $\mathrm{L} / \mathrm{M}$ cells. We propose that a second, much smaller population is made up of individual midget bipolar cells that receive input from Lor $\mathrm{M}$ cones that are next to an $\mathrm{S}$ cone and that also receive a significant feed-forward input from the neighboring S cone via an HII horizontal cell. This subgroup may represent between $5 \%$ and $15 \%$ of the total midget ganglion cell population, and we propose that these cells are responsible for conscious color perception in primates. In our model (illustrated in Fig. 2), $\mathrm{S}$ cone signals are combined with $\mathrm{L}$ and $\mathrm{M}$ opponent signals in the outer retina to produce a small population of bipolar cells that provide the origins of what become four labeled lines for the four unique hues (Schmidt et al. 2014).

This new theory of the neural circuitry for primate color vision makes it easy to explain how gene therapy cures red-green color blindness: The addition of an opsin gene recapitulates the circuitry of normal trichromacy by converting the formerly blue-yellow system with two circuits, one for blue and one for yellow, into four circuits. The former blue circuit is split into red and blue circuits, and the former yellow circuit is split into yellow- and green circuits. According to this hypothesis, blue-yellow color vision in the untreated, dichromatic 


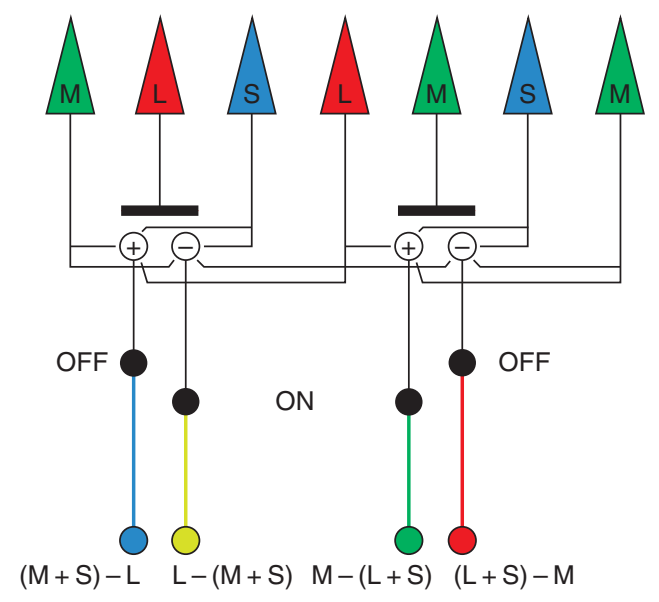

Figure 2. Schematic representation of the blue-yellow midget ganglion cell theory. A blue-yellow system that is separate from the $\mathrm{S}-(\mathrm{M}+\mathrm{L})$ small bistratified cell system is proposed to have evolved in primates for the purpose of conscious color vision (Schmidt et al. 2014). In a dichromatic monkey, midget bipolar cells that contact $\mathrm{M}$ cones that are adjacent to $\mathrm{S}$ cones differentiate $\mathrm{S}$ and $\mathrm{M}$ signals via the inverse sign between a GABA-mediated feed-forward from $\mathrm{S}$ cones via HII horizontal cells and the direct feed-forward from $\mathrm{M}$ cones to the bipolar cell. S-ON and S-OFF signals responsible for the sensations of blue and yellow, respectively, are produced by signaling through $\mathrm{ON}$ and OFF bipolar cells. The introduction of $\mathrm{L}$ cones splits the system in two. $\mathrm{M}$ cone centers are responsible for red and green sensation via OFF and $\mathrm{ON}$ midget bipolar cells, and L cone centers mediate blue and yellow sensations via OFF and ON midget bipolar cells, respectively.

animals is served by a subset of midget ganglion cells that have S-cone input via GABA-mediated feed forward. Receptive fields for midget ganglion cells with direct input from $\mathrm{M}$ cones to bipolar cells and sign-inverted S-cone input from GABA-mediated feed forward via HII horizontal cells mediate the perception of blue by transmitting S-ON signals through the OFF midget bipolar cell. The same receptive fields mediate the perception of yellow via the ON midget bipolar cell. In the treated animals (Fig. 2), receptive fields that combine inputs from virally transduced " $L$ " cones and sign-inverted inputs from $\mathrm{S}$ and $\mathrm{M}$ cones are responsible for the perception of blue via $(\mathrm{S}+\mathrm{M})$-ON signals transmitted to the OFF midget bipolar cells, and the same receptive fields are responsible for the perception of yellow via L-ON signals transmitted through the ON midget bipolar cells of the central "L" cone. Red-green color vision in the treated animals is conferred by receptive fields, with an untransduced $\mathrm{M}$ cone providing direct input to the midget bipolar cell and $S$ plus-transduced "L" cones providing sign-inverted input via GABA-mediated feed forward. In this case, the percept of red is mediated by the OFF midget bipolar neuron that receives $(\mathrm{S}+\mathrm{L})-\mathrm{ON}$ input via the GABA-mediated HII horizontal cell feed-forward mechanism. The same receptive field mediates the perception of green via the $\mathrm{ON}$ midget bipolar cell receiving input directly from the $\mathrm{M}$ cone.

\section{CURING COLOR BLINDNESS IN MICE COMPARED WITH PRIMATES}

Trichromacy exists as a normal trait among some members of the squirrel monkey species. Thus, dichromacy exists as a variant in the monkey population much like it does in humans. The difference between squirrel monkeys and humans, however, is that although $\sim 7 \%-8 \%$ of human males have some form of color vision deficiency, all male squirrel monkeys have a dichromatic form of color blindness and only a subset of females are trichromats. Is there something about the visual system in animals like squirrel monkeys, which already have trichromatic members that makes it especially permissive to the addition of trichromacy by gene therapy? What would happen if the same experiments were performed in a species that was uniformly dichromatic?

The latter question has been addressed in a series of experiments in which genetic manipulations were used to generate trichromatic mice (Smallwood et al. 2003). "Knock-in" mice were made by replacing the endogenous M-cone opsin gene (spectral peak $\sim 511 \mathrm{~nm}$ ) with one encoding human L opsin (spectral peak $\sim 555 \mathrm{~nm}$ ) (Jacobs et al. 1991). The knock-in mice were mated to wild-type mice to produce heterozygous females in which $\mathrm{X}$ inactivation produced two middle-to-long wavelength cone submosaics, as occurs naturally in female squirrel mon- 
keys, and some of the heterozygous mice gained red-green color vision capacities (Jacobs et al. 2007). Interestingly, red-green color vision in the mice was very weak compared with that shown by humans with normal trichromacy or by the monkeys treated with gene therapy; it was so weak, in fact, that it was not detected in two of the five mice tested. This shows that in a species entirely lacking red-green color vision it is possible to get some trichromatic behavior simply by adding a new cone subpopulation; however, the capacity is extremely poor compared with primates with the new M-plus-L cone.

Presumably, allelic trichromacy in New World monkeys evolved from a mutation that changed the spectral sensitivity of the pigment produced by the opsin gene on the $\mathrm{X}$ chromosome, allowing a heterozygous female to have two spectrally distinct populations of cones and providing the basis for red-green color vision. In squirrel monkeys, the three different $\mathrm{X}$ chromosome opsin alleles are present at equal frequency in the population. This is consistent with the idea that the selective advantages associated with red-green color vision maximized the number of trichromats in the population. Primates are the only mammals that have redgreen color vision. If trichromacy could arise in other mammals by a single point mutation in the opsin gene on the $\mathrm{X}$ chromosome, it seems likely that there would be many more mammals with at least allelic trichromacy. Thus, we conclude that changes in a primate ancestor's visual system for purposes other than red-green color vision occurred before the mutation that added the extra L/M photopigment could be opportunistically used to produce the dramatically better color vision of primate trichromacy (Wassle and Boycott 1991). These changes presumably include the evolution of the midget bipolar/ganglion cell system in primates, in which every cone in the central retina is associated with a private line from the retina to the central nervous system. In addition, as discussed above, our primate ancestors may have evolved a blue-yellow color vision system separate from the ancient small bistratified ganglion cell/koniocellular blue-yellow pathway in the lateral geniculate nucleus. Although the primitive ko- niocellular blue-yellow system may serve in the guidance of navigational movements, we might not have direct conscious awareness of the signals. The putative primate-specific blue-yellow system includes a GABA-mediated feed-forward pathway from $S$ cones to midget bipolar cells, and we speculate that it provides the basis for conscious color vision in the ventral stream.

We suggest that once the midget ganglion cell-based blue-yellow system for color vision in the ventral stream was established in our primate ancestor, the addition of the third cone type split the system into two pathways, one for red-green color vision and the other for blue-yellow color vision (Neitz and Neitz 2011; Schmidt et al. 2014). Moreover, we suggest that the evolution of red-green color vision has been recapitulated in the acquisition of red-green color vision by gene therapy. Normally, the signals in the ventral stream are attached to specific meanings through a process of learning. Thus, the acquisition of red-green color vision would not require any rewiring, but presumably treated animals would have to learn that the subset of blue-yellow signaling neurons that are transformed to red-green signaling neurons carry a new meaning.

\section{MEANS OF DELIVERY FOR GENE THERAPY: SUBRETINAL VERSUS INTRAVITREAL INJECTION}

Previously, in treating red-green color blindness in primates, virus was injected into the subretinal space (the region between the retinal pigment epithelium and the photoreceptors) because it was the only way to ensure that the virus would have access to photoreceptors; however, subretinal injections carry risk of retinal damage (Maguire et al. 2008; Nork et al. 2012), which would be eliminated if the virus could effectively transduce cones when injected into the vitreous. If gene therapy is to be a viable option to cure color blindness in humans, the benefits must outweigh the risks. A major step toward reducing risk from the procedure will come from developing viruses that will transduce cones following a simple injection into the vitreous chamber of the eye; however, naturally oc- 
curring adeno-associated virus serotypes do not penetrate to the outer retina effectively when injected into the vitreous (Dalkara et al. 2009).

Recent efforts to develop viruses that can penetrate to the outer retina when injected into the vitreous have shown promising results (Petrs-Silva et al. 2009; Dalkara et al. 2013). AAV viruses with tyrosine mutations exposed at the surface allow the virus to escape degradation by cellular pathways, and in rodents these viruses penetrated and transduced photoreceptors when injected into the vitreous (Petrs-Silva et al. 2009; Petrs-Silva et al. 2011). However, in our preliminary experiments there was limited improvement in the extent or pattern of cells in the primate retina (macaque and baboon) transduced by tyrosine-mutated AAV2 as opposed to wild-type AAV2, or for tyrosine-mutated AAV5 compared with wild-type AAV5 (ARVO abstract) (Di et al. 1987).

Several labs have shown success using in vitro and in vivo selection to develop gene therapy vectors that target specific cell types (Muller et al. 2003; Perabo et al. 2003). In recent work, directed in vivo evolution of AAV2 libraries in the mouse retina was used to identify mutant viruses that could transduce outer retinal cells, notably photoreceptors, with greater efficiency when injected into the vitreous (Dalkara et al. 2013). Three AAV libraries were combined and injected into the vitreous of mice. One library was a collection of capsids with random oligonucleotides encoding 7 mer peptides inserted in the heparin-binding domain of the capsid; a second library carried a tyrosine mutant version of the viral genome that was subjected to random mutagenesis; and the third was a chimeric capsid-encoding library generated by shuffling AAV $1,-2,-4,-5,-6,-8$, and -9 . The combined libraries were injected into transgenic mice with GFP-labeled rods. The GFP-expressing cells were sorted using flow cytometry. The viral DNA was then recovered from the photoreceptors, packaged into virus and again injected into mice. This process was repeated to complete several rounds of viral evolution in which virus was recovered from photoreceptors, subjected to error-prone polymerase chain reactions to introduce further genetic diversity, and reinject- ed into mice. Of the AAV variants obtained using this approach, the majority were from the 7 mer library and shared the same 7 -amino-acid motif (LGETTRP), designated $7 \mathrm{~m} 8$. When injected into the vitreous of mouse eyes, the $7 \mathrm{~m} 8$ variant transduced photoreceptors with much higher efficiency than did a tyrosine-mutated AAV2. When the $7 \mathrm{~m} 8$ variant of AAV 2 carrying GFP was injected into the vitreous of macaque eyes, there were patchy spots of transduced photoreceptors in the peripheral retina (Dalkara et al. 2013). This approach shows great promise for recovering virus with capsid mutations that allow efficient penetration to the outer retina and transduction of photoreceptors when injected into the vitreous.

Gene therapy promises great benefits in the treatment of both rod- and cone- photoreceptor-based vision disorders. These include blue cone monochromacy, which is often caused by mutations in opsin genes or by the deletion of the locus control region, an enhancer critically important for transcription of the adjacent cone opsin genes (Nathans et al. 1989; Nathans et al. 1993). Blue cone monochromats have no functioning L- or M cones, and must rely entirely on $\mathrm{S}$ cones for photopic vision; as a consequence, they have low vision and no color vision. Deletions of the locus control region impairs function of cone photoreceptors, but adaptive optics imaging suggests that at least some fraction of $\mathrm{L} / \mathrm{M}$ cones remain viable and amenable to gene therapy (Carroll et al. 2012; Cideciyan et al. 2013). Likewise, for the cone opsin mutation designated LIAVA ( for the combination of amino acids specified by five polymorphic codons in exon 3 ), the cones are rendered nonfunctional but they do not appear to degenerate (Carroll et al. 2004). For these and a host of other retinal degenerations affecting photoreceptors, a virus that effectively transduces photoreceptors and cells of the retinal pigment epithelium when injected into the vitreous would have great benefit.

\section{CONCLUDING REMARKS}

The most-common inherited defects for redgreen color vision in humans arise from gene rearrangements in which all genes encoding the 
L- or M-cone opsin have been either deleted or displaced to a nonexpressed position in the array (Nathans et al. 1986a; Hayashi et al. 1999). The cause of red-green color blindness in squirrel monkeys - the presence of a single opsin gene on the X chromosome-is thus genetically identical to that in a subset of humans. The number of humans with red-green color vision defects is large-one in twelve males and one in $\sim 230$ females. One day, gene therapy methods may be sufficiently safe and practical that it will be possible to treat people for whom color blindness is a detriment to their quality of life. However, red-green color blindness can also be caused by point mutations in the cone opsin genes (Winderickx et al. 1992; Neitz et al. 2004; Carroll et al. 2009, 2012; Wagner-Schuman et al. 2010), which in some cases are associated with cone dystrophy (Gardner et al. 2010; McClements et al. 2013), leading to debilitating vision loss in addition to color vision deficits. It remains to be seen whether the gene therapy approach used in squirrel monkeys could rescue cone dystrophy caused by mutations in cone photopigment genes. Also, more debilitating than red-green color blindness is blue cone monochromacy. There is evidence with some mutations that at least some cones may remain viable into adulthood (Carroll et al. 2012; Cideciyan et al. 2013), making this disorder amenable to gene therapy, at least in a subset of cases.

In the broader scope, results from experiments to cure color blindness in mice and nonhuman primates provide important lessons about how preexisting circuitry may be exploited in response to new inputs added in adulthood. The unique capacity of the primate brain to adapt to new inputs by learning new associations may provide a mechanism for new capacities to be added in humans via gene therapy.

\section{ACKNOWLEDGMENTS}

Work described in this paper was funded by the National Eye Institute (NEI) grants R01EY016861, R01EY009303, R01EY009620, and P30EY001730; by the Washington National Primate Research Center (WaNPRC) through National Institutes of Health (NIH) grant
P51OD010425; and Research to Prevent Blindness. J.N. is the Bishop Professor of Ophthalmology, and M.N. is the Ray H. Hill Professor of Ophthalmology.

\section{REFERENCES}

Albright TD, Jessell TM, Kandel ER, Posner MI. 2000. Neural science: A century of progress and the mysteries that remain. Cell 100: S1-S55.

Birch EE, Stager DR. 1996. The critical period for surgical treatment of dense congenital unilateral cataract. Invest Ophthalmol Vis Sci 37: 1532-1538.

Brainard DH, Roorda A, Yamauchi Y, Calderone JB, Metha A, Neitz M, Neitz J, Williams DR, Jacobs GH. 2000. Functional consequences of the relative numbers of $\mathrm{L}$ and $\mathrm{M}$ cones. J Opt Soc Am A Opt Image Sci Vis 17: 607-614.

Bunce J, Isbell L, Neitz M, Bonci D, Surridge A, Jacobs G, Smith D. 2011. Characterization of opsin gene alleles affecting color vision in a wild population of titi monkeys (Callicebus brunneus). Am J Primatol 73: 189-196.

Carroll J, McMahon C, Neitz M, Neitz J. 2000. Flicker-photometric electroretinogram estimates of L: M cone photoreceptor ratio in men with photopigment spectra derived from genetics. J Opt Soc Am A Opt Image Sci Vis 17: 499-509.

Carroll J, Neitz M, Wolfing J, Gray D, Neitz J, Williams DR. 2004. Different genetic causes of red-green color blindness give rise to different retinal phenotypes as assessed with adaptive optics. Invest Ophthalmol Vis Sci 45: U426-U426.

Carroll J, Baraas RC, Wagner-Schuman M, Rha J, Siebe CA, Sloan C, Tait DM, Thompson S, Morgan JIW, Neitz J, et al. 2009. Cone photoreceptor mosaic disruption associated with Cys203Arg mutation in the M-cone opsin. Proc Natl Acad Sci 106: 20948-20953.

Carroll J, Dubra A, Gardner JC, Mizrahi-Meissonnier L, Cooper RF, Dubis AM, Nordgren R, Genead M, Connor TB Jr, Stepien KE, et al. 2012. The effect of cone opsin mutations on retinal structure and the integrity of the photoreceptor mosaic. Invest Ophthalmol Vis Sci 53: 8006-8015.

Cideciyan AV, Hufnagel RB, Carroll J, Sumaroka A, Luo X, Schwartz SB, Dubra A, Land M, Michaelides M, Gardner JC, et al. 2013. Human cone visual pigment deletions spare sufficient photoreceptors to warrant gene therapy. Hum Gene Ther 24: 993-1006.

Dacey DM. 2000. Parallel pathways for spectral coding in primate retina. Ann Rev Neurosci 23: 743-775.

Dalkara D, Kolstad K, Caporale N, Visel M, Klimczak R, Schaffer D, Flannery J. 2009. Inner limiting membrane barriers to AAV-mediated retinal transduction from the vitreous. Mol Ther 17: 2096-2102.

Dalkara D, Byrne LC, Klimczak RR, Visel M, Yin L, Merigan WH, Flannery JG, Schaffer DV. 2013. In vivo directed evolution of a new adeno-associated virus for therapeutic outer retinal gene delivery from the vitreous. Sci Trans Med 5: 189ra76.

DeValois RL, DeValois KK. 1993. A multi-stage color model. Vision Res 33: 1053-1065. 
Di S, Neitz J, Jacobs GH. 1987. Early color deprivation and subsequent color vision in a dichromatic monkey. Vision Res 27: 2009-2013.

Drum B. 1989. Hue signals from short- and medium-wavelength sensitive cones. J Opt Soc Am A Opt Image Sci Vis 6: $153-156$.

Dryja TP, McGee TL, Berson EL, Fishman GA, Sandberg MA, Alexander KR, Derlacki DJ, Rajagopalan AS. 2005. Night blindness and abnormal cone electroretinogram ON responses in patients with mutations in the GRM6 gene encoding mGluR6. Proc Natl Acad Sci 102: 48844889.

Gardner J, Webb T, Kanuga N, Robson A, Holder G, Stockman A, Ripamonti C, Ebenezer N, Ogun O, Devery S, et al. 2010. X-linked cone dystrophy caused by mutation of the red and green cone opsins. Am J Hum Genet 87: 26-39.

Hagstrom SA, Neitz J, Neitz M. 1998. Variations in cone populations for red-green color vision examined by analysis of mRNA. NeuroReport 9: 1963-1967.

Hayashi T, Motulsky AG, Deeb SS. 1999. Position of a 'greenred' hybrid gene in the visual pigment array determines colour-vision phenotype. Nat Genet 22: 90-93.

Hofer H, Carroll J, Neitz J, Neitz M, Williams DR. 2005. Organization of the human trichromatic cone mosaic. Neurosci 25: 9669-9679.

Hubel DH. 1988. Eye, Brain, and Vision. W.H. Freeman and Company, New York.

Hubel DH, Wiesel TN. 1970. The period of susceptibility to the physiological effects of unilateral eye closure in kittens. J Physiol 206: 419-436.

Jacobs GH. 1984. Within-species variations in visual capacity among squirrel monkeys (Saimiri sciureus): Color vision. Vision Res 24: 1267-1277.

Jacobs GH, Neitz J. 1985. Color vision in squirrel monkeys: Sex-related differences suggest the mode of inheritance. Vision Res 25: 141-143.

Jacobs GH, Neitz J. 1987. Inheritance of color vision in a New World monkey (Saimiri sciureus). Proc Natl Acad Sci 84: $2545-2549$.

Jacobs GH, Neitz J, Deegan JF II. 1991. Retinal receptors in rodents maximally sensitive to ultraviolet light. Nature 353: 655-656.

Jacobs GH, Neitz J, Neitz M. 1993. Genetic basis of polymorphism in the color vision of platyrrhine monkeys. Vision Res 33: 269-274.

Jacobs GH, Williams GA, Cahill H, Nathans J. 2007. Emergence of novel color vision in mice engineered to express a human cone photopigment. Science 315: 1723-1725.

Jordan G, Mollon JD. 1997. Unique hues in heterozygotes for protan and deutan deficiencies. In Colour Vision Deficiencies XIII (ed. Cavonius CR), pp. 67-76. Kluwer Academic Publishers, Dordrecht, Netherlands.

Khanna RC, Foster A, Krishnaiah S, Mehta MK, Gogate PM. 2013. Visual outcomes of bilateral congenital and developmental cataracts in young children in south India and causes of poor outcome. Indian J Ophthalmol 61: 65-70.

Kuchenbecker J, Sahay M, Tait DM, Neitz M, Neitz J. 2008. Topography of the long- to middle-wavelength sensitive cone ratio in the human retina assessed with a wide-field color multifocal electroretinogram. Vis Neurosci 25: 301-306.

Li Q, Timmers AM, Guy J, Pang J, Hauswirth WW. 2007. Cone-specific expression using a human red opsin promoter in recombinant AAV. Vision Res 48: 332-338.

Maguire AM, Simonelli F, Pierce EA, Pugh ENJ, Mingozzi F, Bennicelli J, Banfi S, Marshall KA, Testa F, Surace EM, et al. 2008. Safety and efficacy of gene transfer for Leber's congenital amaurosis. N Engl J Med 358: 2240-2248.

Makous W. 2007. Comment on "Emergence of novel color vision in mice engineered to express a human cone photopigment." Science 318: 196.

Mancuso K, Neitz M, Neitz J. 2006. An adaptation of the Cambridge Colour Test for use with animals. Vis Neurosci 23: 695-701.

Mancuso K, Hauswirth WW, Li Q, Connor TB, Kuchenbecker JA, Mauck MC, Neitz J, Neitz M. 2009. Gene therapy for red-green colour blindness in adult primates. Nature 461: 784-787.

McClements M, Davies WI, Michaelides M, Carroll J, Rha J, Mollon JD, Neitz M, MacLaren RE, Moore AT, Hunt DM. 2013. X-linked cone dystrophy and colour vision deficiency arising from a missense mutation in a hybrid L/M cone opsin gene. Vision Res 80: 41-50.

Miyahara E, Pokorny J, Smith VC, Baron R, Baron E. 1998. Color vision in two observers with highly biased LWS/ MWS cone ratios. Vision Res 38: 601-612.

Mollon JD, Bowmaker JK, Jacobs GH. 1984. Variations of colour vision in a New World primate can be explained by polymorphism of retinal photopigments. Proc R Soc Lond B Biol Sci 222: 373-399.

Muller OJ, Kaul F, Weitzman MD, Pasqualini R, Arap W, Kleinschmidt JA, Trepel M. 2003. Random peptide libraries displayed on adeno-associated virus to select for targeted gene therapy vectors. Nat Biotechnol 21: 10401046.

Nathans J, Piantanida TP, Eddy RL, Shows TB, Hogness DS. 1986a. Molecular genetics of inherited variation in human color vision. Science 232: 203-210.

Nathans J, Thomas D, Hogness DS. 1986b. Molecular genetics of human color vision: The genes encoding blue, green, and red pigments. Science 232: 193-202.

Nathans J, Davenport CM, Maumenee IH, Lewis RA, Hejtmancik JF, Litt M, Lovrien E, Weleber R, Bachynski B, Zwas F, et al. 1989. Molecular genetics of human blue cone monochromacy. Science 245: 831-838.

Nathans J, Maumenee IA, Zrenner E, Sadowski B, Sharpe LT, Lewis RA, Hansen E, Rosenberg P, Schwartz M, Heckenlively JR, et al. 1993. Genetic heterogeneity among bluecone monochromats. Am J Hum Genet 53: 987-1000.

Neitz J, Neitz M. 2011. The genetics of normal and defective color vision. Vision Res 51: 633-651.

Neitz M, Neitz J, Jacobs GH. 1991. Spectral tuning of pigments underlying red-green color vision. Science 252: 971-974.

Neitz M, Carroll J, Renner A, Knau H, Werner JS, Neitz J. 2004. Variety of genotypes in males diagnosed as dichromatic on a conventional clinical anomaloscope. Vis Neurosci 21: 205-216.

Nork TM, Murphy CJ, Kim CB, Ver Hoeve JN, Rasmussen CA, Miller PE, Wabers HD, Neider MW, Dubielzig RR, 
McCulloh RJ, et al. 2012. Functional and anatomic consequences of subretinal dosing in the cynomolgus macaque. Arch Ophthalmol 130: 65-75.

Perabo L, Buning H, Kofler DM, Ried MU, Girod A, Wendtner CM, Enssle J, Hallek M. 2003. In vitro selection of viral vectors with modified tropism: The adeno-associated virus display. Mol Ther 8: 151-157.

Petrs-Silva H, Dinculescu A, Li Q, Min S, Chiodo V, JJ P, Zhong L, Zolotukhin S, Srivastava A, Lewin A, et al. 2009. High-efficiency transduction of the mouse retina by tyrosine-mutant AAV serotype vectors. Mol Ther 17: 463-471.

Petrs-Silva H, Dinculescu A, Li Q, Deng W, Pang J, Min S, Chiodo V, Neeley A, Govindasamy L, Debbett A, et al. 2011. Novel properties of tyrosine-mutant AAV2 vectors in the mouse retina. Mol Ther 19: 293-301.

Pokorny J, Smith VC, Wesner MF. 1991. Variability in cone populations and implications. In From Pigments to Perception: Advances in Understanding Visual Processes (ed. Valberg A, Lee BB), pp. 23-33. Plenum Press, New York.

Puller C, Haverkamp S, Neitz M, Neitz J. 2014a. Synaptic elements for GABAergic feed-forward signaling between HII horizontal cells and blue cone bipolar cells are enriched beneath primate S-cones. PloS ONE 9: e288963.

Puller C, Manookin MB, Neitz M, Neitz J. 2014b. Specialized synaptic pathway for chromatic signals beneath S-cone photoreceptors is common to human, Old and New World primates. J Opt Soc Am A Opt Image Sci Vis 31: A189-A194.

Reffin JP, Astell S, Mollon JD. 1991. Trials of a computercontrolled colour vision test that preserves the advantages of pseudo-isochromatic plates. In Colour Vision Deficiencies X (ed. Drum B, Moreland JD, Serra A), pp. 69-76. Kluwer Academic Publishers, Dordrecht, Netherlands.

Regan BC, Reffin JP, Mollon JD. 1994. Luminance noise and the rapid determination of discrimination ellipses in colour deficiency. Vision Res 34: 1279-1299.

Roorda A, Williams DR. 1999. The arrangement of the three cone classes in the living human eye. Nature 397: $520-522$.
Schmidt BP, Neitz M, Neitz J. 2014. Neurobiological hypothesis of color appearance and hue perception. J Opt Soc Am 31: A195-A207.

Shapley R. 2009. Vision: Gene therapy in colour. Nature 461: 737-739.

Smallwood PM, Olveczky BP, Williams GL, Jacobs GH, Reese BE, Meister M, Nathans J. 2003. Genetically engineered mice with an additional class of cone photoreceptors: Implications for the evolution of color vision. Proc Natl Acad Sci 100: 11706-11711.

Soares J, Fiorani M, Araujo E, Zana Y, Bonci D, Neitz M, Ventura D, Gattass R. 2010. Cone photopigment variations in Cebus apella monkeys evidenced by electroretinogram measurements and genetic analysis. Vision Res 50: $99-106$.

Tailby C, Solomon SG, Lennie P. 2008. Functional asymmetries in visual pathways carrying S-cone signals in macaque. J Neurosci 28: 4078-4087.

Terasaki H, Miyake Y, Nomura R, Horiguchi M, Suzuki S, Kondo M. 1999. Blue-on-yellow perimetry in the complete type of congenital stationary night blindness. Invest Ophthalmol Vis Sci 40: 2761-2764.

Vollrath D, Nathans J, Davis RW. 1988. Tandem array of human visual pigment genes at Xq28. Science 240: 1669-1672.

Wagner-Schuman M, Neitz J, Rha J, Williams DR, Neitz M, Carroll J. 2010. Color-deficient cone mosaics associated with Xq28 opsin mutations: A stop codon versus gene deletions. Vision Res 50: 2396-2402.

Wang Y, Macke JP, Merbs SL, Zack DJ, Klaunberg B, Bennett J, Gearhart J, Nathans J. 1992. A locus control region adjacent to the human red and green visual pigment genes. Neuron 9: 429-440.

Wang Y, Smallwood PM, Cowan M, Blesh D, Lawler A, Nathans J. 1999. Mutually exclusive expression of human red and green visual pigment-reporter transgenes occurs at high frequency in murine cone photoreceptors. Proc Natl Acad Sci 96: 5251-5256.

Wassle H, Boycott BB. 1991. Functional architecture of the mammalian retina. Physiol Rev 71: 447-480.

Winderickx J, Sanocki E, Lindsey DT, Teller DY, Motulsky AG, Deeb SS. 1992. Defective colour vision associated with a missense mutation in the human green visual pigment gene. Nat Genet 1: 251-256. 


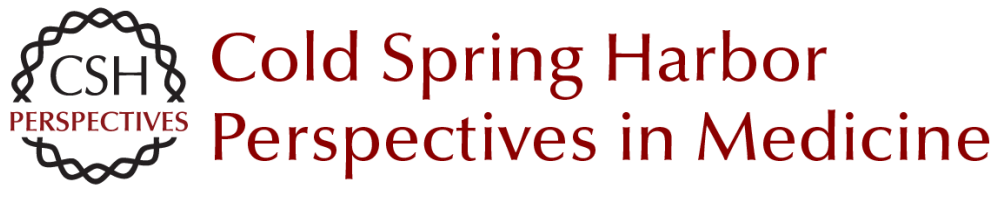

\section{Curing Color Blindness--Mice and Nonhuman Primates}

Maureen Neitz and Jay Neitz

Cold Spring Harb Perspect Med 2014; doi: 10.1101/cshperspect.a017418 originally published online August 21, 2014

\section{Subject Collection Retinal Disorders: Genetic Approaches to Diagnosis and Treatment}

Trial by "Firsts": Clinical Trial Design and Regulatory Considerations in the Development and Approval of the First AAV Gene Therapy Product in the United States

Kathleen Z. Reape and Katherine A. High

Immunology of Retinitis Pigmentosa and Gene Therapy-Associated Uveitis

Paul Yang, Debarshi Mustafi and Kathryn L. Pepple

Developing New Vectors for Retinal Gene Therapy

Emilia A. Zin, Bilge E. Ozturk, Deniz Dalkara, et al.

Beyond the NEI-VFQ: Recent Experience in the Development and Utilization of Patient-Reported Outcomes for Inherited Retinal Diseases

Todd Durham, Judit Banhazi, Francesco Patalano, et al.

Electronic Retinal Prostheses

Daniel Palanker

Alternative RNA Splicing in the Retina: Insights and Perspectives

Casey J. Keuthan, Sadik Karma and Donald J. Zack

X-Linked Retinoschisis

Cristy A. Ku, Lisa W. Wei and Paul A. Sieving

A Systematic Review of Optogenetic Vision Restoration: History, Challenges, and New Inventions from Bench to Bedside

Antonia Stefanov and John G. Flannery
Lessons Learned from the Development of the

First FDA-Approved Gene Therapy Drug,

Voretigene Neparvovec-rzyl Jean Bennett and Albert M. Maguire

Therapeutic Gene Editing in Inherited Retinal Disorders Jinjie Ling, Laura A. Jenny, Ashley Zhou, et al.

Cell-Based Therapies: Strategies for Regeneration Marina Pavlou and Thomas A. Reh

The Importance of Natural History Studies in Inherited Retinal Diseases

Allison Ayala, Janet Cheetham, Todd Durham, et al.

Photoreceptor Cell Replacement Using

Pluripotent Stem Cells: Current Knowledge and Remaining Questions

Christelle Monville, Olivier Goureau and Karim Ben M'Barek

iPSC-RPE in Retinal Degeneration: Recent

Advancements and Future Perspectives

Tadao Maeda and Masayo Takahashi

Retinal Degeneration Animal Models in Bardet-

Biedl Syndrome and Related Ciliopathies Clarisse Delvallée and Hélène Dollfus

Mobility Testing and Other Performance-Based

Assessments of Functional Vision in Patients with Inherited Retinal Disease

Daniel Chung, Colas Authié and Laure Blouin

For additional articles in this collection, see http://perspectivesinmedicine.cshlp.org/cgi/collection/ 
For additional articles in this collection, see http://perspectivesinmedicine.cshlp.org/cgi/collection/ 